\title{
A Competência Social do Psicólogo: Estudo com Profissionais que Atuam em Instituções
}

Social Competence of Psychologists: Study With Professionals Who Work In Institutions

La Competencia Social Del Psicólogo: Estudio Con Profesionales Que Actúan En Instituciones
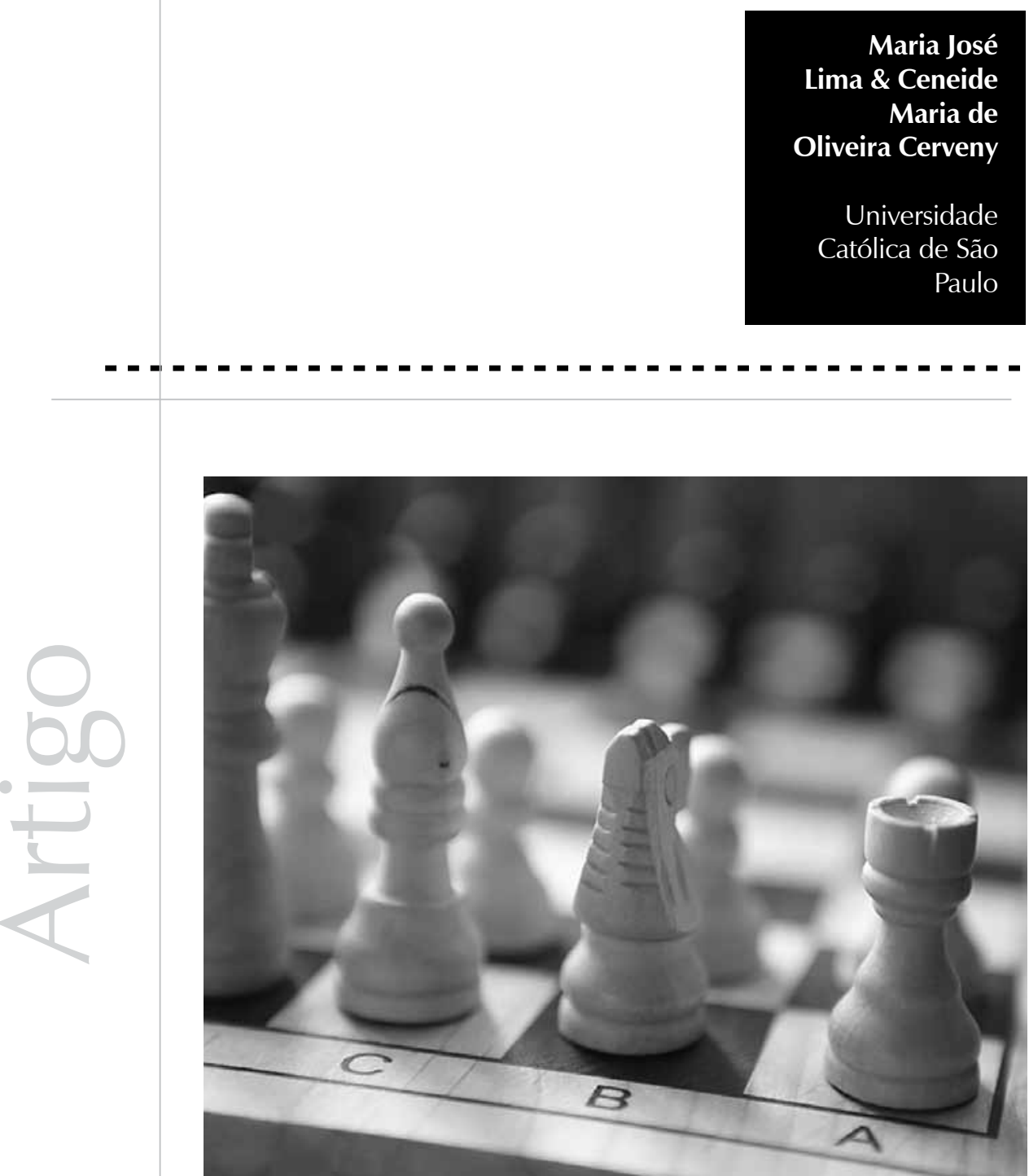
Resumo: Com o objetivo de desenvolver uma análise sobre a percepção de psicólogos em relação à sua competência para trabalhar em instituições que atendem à população que vive em condição de risco, esta pesquisa voltou-se para esse contexto, explorando os recursos desenvolvidos, seus aspectos facilitadores e dificultadores, assim como a compreensão que esses profissionais têm de sua ação, considerando as facetas dos aspectos psicoterapêutico e social. A pesquisa é qualitativa, de nível exploratório descritivo, e fez uso de um questionário de caracterização do participante e da técnica do grupo focal. Os participantes foram psicólogos que atuam em instituições que atendem a população que vive em risco social, em São José dos Campos/SP. A análise do material obtido no grupo baseou-se em algumas ferramentas qualitativas do método de análise de conteúdo. Para a fase de interpretação, foram utilizadas as contribuições teóricas do pensamento sistêmico novo paradigmático. Os resultados apontam a percepção de um lugar em construção, o do psicólogo institucional, em busca de identidade e valorização, assim como da necessidade da criação de competências para o trabalho nesse contexto. Os participantes percebem suas ações como não clínicas e buscam seu lugar na área social, dadas as atuais demandas de maior comprometimento em contextos de maior vulnerabilidade.

Palavras-chave: Atuação do psicólogo. Competência. Social. Psicologia social.

Abstract:: Aiming to develop an analysis of the psychologists' perception about their ability to work in institutions that serve the population who lives in conditions of risk, this research was directed to this context, exploiting the resources developed, their advantages and constraints as well as the way these professionals see their action, considering psychotherapy and the social aspects. This is a qualitative research of exploratory and descriptive level, and it made use of a questionnaire and focus on group technique. The participants were psychologists who worked in institutions that serve the population who live in social risk, in São José dos Campos/SP. The analysis of the material obtained in the group was based on qualitative tools of the content analysis method. For the interpretation phase, we used the theoretical contributions of the new paradigm system. The results point to the perception of a place in construction, the institutional psychologist in search of identity and enhancement, as well as the need to develop skills to work in that context. The participants perceive their actions as non-clinical and seek their place in social work, given the current demands for greater involvement in contexts of vulnerability. Keywords: Psychologist performance. Competence. Social. Social psychology.

Resumen: Con el objetivo de desarrollar un análisis sobre la percepción de psicólogos en relación a su competencia para trabajar en instituciones que atienden a la población que vive en condición de riesgo, esta pesquisa se volcó hacia ese contexto, explorando los recursos desarrollados, sus aspectos facilitadores y dificultadores, así como la comprensión que esos profesionales tienen de su acción, considerando las facetas de los aspectos psicoterapéutico y social. La pesquisa es cualitativa, de nivel exploratorio descriptivo, e hizo uso de un cuestionario de caracterización del participante y de la técnica del grupo focal. Los participantes fueron psicólogos que actúan en instituciones que atienden a la población que vive en riesgo social, en São José dos Campos/SP. El análisis del material obtenido en el grupo se basó en algunas herramientas cualitativas del método de análisis de contenido. Para la fase de interpretación, fueron utilizadas las contribuciones teóricas del nuevo pensamiento sistémico paradigmático. Los resultados apuntan la percepción de un lugar en construcción, el del psicólogo institucional, en busca de identidad y valorización, así como de la necesidad de la creación de competencias para el trabajo en ese contexto. Los participantes perciben sus acciones como no clínicas y buscan su lugar en el área social, dadas las actuales demandas de mayor comprometimiento en contextos de mayor vulnerabilidad.

Palabras clave: Actuación del psicólogo. Competencia. Psicologia social. Psicología social.

A Psicologia brasileira tem avançado na construção de sua identidade, impulsionada por uma série de fatores, e tem vivido as ressonâncias de um mundo pós-moderno tanto em sua prática, que se depara frente a frente com o novo, como em sua construção teórica, que lida com a emergência dos novos paradigmas da ciência contemporânea. Dentro de um clima de mudanças, um importante movimento se constrói na direção de um compromisso social, culminando com a orientação de nossos órgãos representativos no sentido de se "fortalecer os vínculos do exercício profissional com as necessidades sociais", conforme deliberação do VI Congresso Nacional de Psicologia (Brasília, 2007).

A inserção do psicólogo junto à rede pública de atendimento à população, desde a década 
Acoplada à ideia de transformação, juntamos à competência o conceito do aspecto social - competência social -, alicerçado na crença da possibilidade de se "produzir mudanças significativas na sociedade a partir de uma ação mais competente em cada espaço profissional" (Rios, 2004, p. 10). de 80 do último século, inaugura uma nova demanda para esse profissional, agora no encontro com a realidade da pobreza e suas consequências na Saúde Mental dos cidadãos, criando a necessidade e o desafio de novas formas de atendimento psicológico quando se trata de trabalhos junto à população pobre.

É perante esse desafio que esta pesquisa tomou emprestado o termo competência da Psicologia organizacional, mas não como um conjunto de requisitos definidos a partir do desenho de um cargo, e sim, como um "conjunto de conhecimento, habilidades e atitudes" (Fleury \& Fleury, 2000, p.185) que possa dar conta da complexidade e da imprevisibilidade do mundo globalizado, uma competência que envolva a capacidade de "transformar os conhecimentos práticos e teóricos adquiridos, quanto mais aumenta a complexidade da situação" (Zarifin, 1999 como citado em Fleury \& Fleury, 2000, p. 187).

Acoplada à ideia de transformação, juntamos à competência o conceito do aspecto social - competência social -, alicerçado na crença da possibilidade de se "produzir mudanças significativas na sociedade a partir de uma ação mais competente em cada espaço profissional" (Rios, 2004, p.10). Um social pensado em sua "interconstituição"com o individual (Grandesso, 2000, p. 104), construindo demandas para uma "psicologia que prioriza o individual e social como complementares" orientando-os "para a complexidade" (p. 110). E passamos a tratar aqui, neste trabalho de pesquisa, da competência social do psicólogo para atuar efetivamente nesse campo de trabalho.

Perante as novas demandas, a atuação psicológica não só tem transitado entre o privado e o público como também entre o individual e o grupo familiar e a comunidade que o cerca, um trânsito que parece estar favorecendo quebras de dicotomias, entre elas, a polarização individual/social, vistas como se fossem objetos diferenciados das diversas áreas de atuação da Psicologia. Essa quebra pode conduzir ao repensar tanto do que seria o individual como do social, e pode contribuir para a construção da competência social do psicólogo.

É desse lugar do psicólogo, visto como novo, que se buscou tratar neste trabalho, que pode colaborar tanto para o conhecimento e a atuação quanto para as reflexões desse profissional que, em nossos dias, em suas rotinas de trabalho, vem construindo um saber e uma prática que aliam o atendimento psicológico às questões sociais. Para essa tarefa, foram utilizadas as contribuições do pensamento sistêmico chamado de novo paradigmático, valendo-se de sua apreensão do mundo a partir da complexidade, que tem favorecido a emergência de questões relativas à especificidade desse trabalho no encontro com o contexto de vida da população atendida.

A relevância social deste projeto de pesquisa construiu-se a partir da importância de se desenvolver um psicólogo competente socialmente, mais comprometido com a promoção de mudanças significativas na vida das pessoas e das suas famílias, saindo das amarras de uma atuação assistencialista que, ao contrário, mantém as pessoas em sua condição.

A relevância científica pode ser vista na possibilidade de seus resultados colaborarem com pesquisadores que trabalham com a formação do psicólogo, no sentido de se pensar em uma formação mínima que melhor atenda as tendências atuais da Psicologia brasileira, de maior compromisso social no que se refere ao desenvolvimento de sua competência para o trabalho com a diversidade sociocultural e de compromisso com a justiça social. Esperase que os resultados também contribuam com o trabalho daqueles que estudam a atuação psicológica no que diz respeito a sua efetividade como ação terapêutica, em seus diversos campos. 
Esta pesquisa, à medida que pretendeu conhecer mais de perto a atuação desse profissional, pode auxiliar na sistematização e no avanço de um trabalho mais eficiente com essa população, aumentando as chances de quebra do chamado ciclo da pobreza (Oliveira, 2003, p. 35), que leva à mendicância e ao consequente aniquilamento da vida familiar.

O objetivo geral da pesquisa ficou assim delineado: desenvolver uma análise sobre a percepção dos psicólogos em torno de sua competência para trabalhar em instituições que atendem a população socialmente vulnerável.

O trabalho norteou-se por seis objetivos específicos: analisar o contexto de trabalho do psicólogo participante a partir da construção de recursos na instituição em que atua, investigar como os psicólogos participantes desta pesquisa entendem sua ação terapêutica no contexto institucional, conhecer e refletir sobre quais são os aspectos percebidos por eles como facilitadores ou dificultadores para o desenvolvimento de seu trabalho, investigar como vêm sendo desenvolvidas e que significado recebem as relações do psicólogo participante com o contexto social da população atendida, investigar o comprometimento social desse psicólogo na construção de suas ações e relações com essa população, conhecer e refletir sobre os conhecimentos, habilidades e atitudes que vêm sendo construídas e, principalmente, avaliadas como úteis para uma atuação socialmente comprometida.

\section{Método}

Foi escolhida a pesquisa do tipo qualitativa, por ser considerada a mais condizente com nosso referencial teórico, associado ao pensamento sistêmico novo paradigmático, que reconhece e legitima o lugar do pesquisador como "parte integrante do processo de conhecimento" (Chizzoti, 2001, p.79), assim como reconhece sua posição de construtor de significados dos fenômenos estudados.
A escolha se justificou ainda por ser condizente com os objetivos da pesquisa, que, sendo do nível exploratório descritivo, propicia o desenvolvimento de uma análise sobre a percepção dos psicólogos a respeito de sua competência para trabalhar em instituições que atendem a população que vive em situação de vulnerabilidade social.

Os participantes foram psicólogos que atuavam em instituições que atendem a população socialmente vulnerável na região de São José dos Campos, SP, conveniadas com a Secretaria de Desenvolvimento Social dessa cidade. Foram selecionadas instituições que, segundo a classificação do Índice Paulista de Vulnerabilidade Social, trabalham junto a comunidades consideradas de média, alta e muito alta vulnerabilidade. Foram abordadas todas as instituições conveniadas com essas condições para, após conhecimento da atuação de um psicólogo, investigar o interesse e a disponibilidade de cada um em participar da pesquisa.

Os instrumentos foram: questionário inicial, com perguntas abertas e fechadas para uma caracterização dos participantes, grupo focal, como forma de coleta de dados, percepções, ideias e valores, realizada através da interação grupal ao se discutir um tópico especial sugerido pelo pesquisador, e um guia de entrevista parcialmente estruturada, construído a partir dos objetivos específicos da presente pesquisa.

Para a análise dos dados, foram utilizadas ferramentas qualitativas do método de análise de conteúdo, partindo da análise temática do conteúdo gerado no grupo focal, que passou por uma categorização inicial cuja análise gerou subcategorias que foram organizadas em quadros para a apresentação dos resultados. Como último passo, as categorias e as respectivas subcategorias foram discutidas à luz das teorias que deram sustentação à pesquisa. 


\section{Resultados e discussão}

O material obtido a cada passo foi apresentado e discutido seguindo o percurso metodológico, desde os primeiros contatos para compor o grupo de participantes, momentos esses que já apresentaram possibilidades de reflexões a respeito do universo do psicólogo nas instituições, até a realização, o registro e a análise do grupo focal.

Durante a fase de composição do grupo de participantes, a pesquisa já revelou um fato surpreendente para uma região considerada uma das mais ricas e desenvolvidas do País: entre as 55 entidades conveniadas à Secretaria do Desenvolvimento Social de São José dos Campos, apenas 12 afirmam ter psicólogos contratados em seu quadro de funcionários, estando as outras, entre as 23 entidades que contam com o trabalho desse profissional, envolvidas com o trabalho voluntário. Algumas afirmaram "não ter mais", e outras ainda afirmam entender como "melhor um assistente social".

Esse quadro nos leva a pensar na não valorização ou até mesmo no não conhecimento do trabalho do psicólogo nesse campo, revelando ainda dificuldades advindas da inserção do trabalho desse profissional junto às instituições. $\mathrm{O}$ ainda se justifica perante a literatura que já, há quase três décadas (Macedo, Kubilikowsky \& Santos, 1985), alerta para um desencontro entre o profissional e a instituição, não sabendo esta o que esperar do psicólogo, que, por sua vez, não estaria preparado para o trabalho em diferentes contextos.

Ao ainda se junta um apesar, pois muito se tem construído a esse respeito, tanto no campo das leis (Brasil, 1993) como no dos estudos acadêmicos, movimento que se concretiza em um importante documento o CREPOP - Centro de Referência Técnica em Psicologia e Políticas Públicas (Brasília,
2006), criado pelo nosso Conselho Federal por meio de seu Sistema Conselhos, que oferece reflexões e diretrizes para a atuação do psicólogo junto à assistência social, na direção do preconizado por nossas avançadas leis, instituídas pela LOAS - Lei Orgânica de Assistência Social (Brasil, 1993).

Destaca-se aqui ainda a questão do voluntarismo, que nos leva a refletir sobre a crescente atuação do chamado Terceiro Setor no País, que, se por um lado vem incrementando a acessibilidade da população aos diversos tipos de serviços, também pode estar incrementando o trabalho não ou mal remunerado dos profissionais. Alertase ainda para o risco de um voluntarismo associado ao assistencialismo, na contramão do preconizado pela LOAS, que abandona um modelo assistencial hegemônico.

Ao serem consultados, dos 23 psicólogos atuantes - contratados e voluntários - restou apenas um pequeno grupo de interessados e disponíveis, que resultou em um grupo de seis participantes, reduzido a cinco no dia da realização do grupo focal.

As respostas dadas aos questionários foram organizadas em oito quadros que apresentam a caracterização e o histórico de formação e de atuação de cada um dos participantes. Para esse relato, cabe aqui destacar que são mulheres, em média de 40 anos, com tempo de trabalho entre 10 e 20 anos. Na descrição de sua caminhada profissional, aparece um grupo que atua em diversas áreas, que já traz o aspecto social e o institucional junto às descrições mais tradicionais das práticas em Psicologia, sendo o consultório particular citado por quatro delas, em uma atuação paralela ao trabalho em instituição.

Da mesma forma, ao descrever seu trabalho junto à instituição representada na pesquisa (sendo duas públicas e três pertencentes ao terceiro setor), citam o atendimento 
clínico entre as principais atividades ali desenvolvidas. O apego ao modelo do consultório pode ser compreendido pelo histórico da Psicologia, que, "construída sob o projeto epistemológico da modernidade" (Grandesso, 2000, p. 54), estaria ainda atrelado ao paradigma biomédico, entendido por Westphal (2007, p. 635) como "vigente e hegemônico até hoje".

Há um destaque para as ações em grupo, citadas por quatro delas, nas quais incluem também a participação em equipes multidisciplinares, assim como as demais atividades que envolvam mais de uma pessoa. É assim que parecem compreender também as relações com a comunidade, não havendo relatos de ações mais abrangentes no que tange à sua organização e funcionamento. A ênfase da pesquisa em comunidade se justifica perante a preocupação que se constrói a partir da ideia de promoção da saúde, que vem dar voz a um novo conceito de saúde, que passa a ser considerada "de forma holística, multideterminada, processual e ligada a direitos básicos do cidadão" (Westphal, 2007, p. 659). Cuidar da saúde, também da mental, significa, portanto, cuidar também do cidadão, considerando os determinantes sociais do processo saúde/ doença.

As participantes desta pesquisa revelam, em suas respostas, um importante traço em comum: são ativas profissionalmente desde a graduação, quando já citam não apenas o trabalho para sustentar a universidade como também estágios alternativos e trabalhos voluntários associados à Psicologia. Deve ser essa a característica que as trouxe para a participação nesta pesquisa, pois apresentaram grande envolvimento com as questões apresentadas ao grupo, em um trabalho de franca e generosa reflexão.

O grupo focal ficou então composto pelas cinco participantes - psicólogas que atuam em instituições -, pelo moderador (pesquisador), responsável pela condução e foco nos objetivos da pesquisa, auxiliado por um comoderador, colega psicóloga inteirada da pesquisa, assim como pela assistente, que auxiliou na gravação e posterior transcrição do material. A duração foi de duas horas e quinze minutos.

$\mathrm{Na}$ análise do material feita a partir dos temas emergentes, foram construídas oito categorias, sendo cada uma delas, por sua vez, analisada em uma "classificação progressiva dos elementos" (Oliveira, 2008, p. 02) que resultou em subcategorias. Os resultados foram apresentados em oito quadros que, não cabendo neste relato, serão aqui apenas sumariados e discutidos.

A categoria 1, cujo tema - a motivação para o trabalho institucional - as instiga desde o começo, traz importantes elementos para avaliar o lugar do psicólogo na instituição. A subcategoria necessidade de ajudar, apoiada em relatos de "inconformismo" frente "às desigualdades sociais", emerge com força e gera inquietação e polêmica, com resistências declaradas à palavra ajudar. Mas fica evidente o poder motivacional da necessidade de ajudar para a inserção desse grupo no trabalho institucional, assim como a busca de uma alternativa à clínica individual, que trata da insatisfação com esse tipo de atividade e que dá preferência às ações grupais. Citam ainda as "experiências na formação", referindo-se às aulas e aos estágios na "área social".

A adesão ao trabalho, no sentido de motivação para sua continuidade, aparece como construída na ação, com depoimentos de recursos sendo criados, conhecimentos construídos e aprendizados realizados na "troca" com a comunidade. Nesse momento, já apontam a falta de formação para o trabalho nesse contexto, com a constante demanda de se criar recursos, assim como apontarão essa falha em outros pontos de nossa conversa. 
O envolvimento construído na prática também se revela na categoria 2 - o comprometimento social do psicólogo - que emergiu das reflexões a respeito de como entendem e avaliam seu comprometimento social com o trabalho. Os depoimentos tratam de uma abertura do profissional para questões que tradicionalmente não fariam parte de seu universo de trabalho. $\mathrm{O}$ desafio produtivo da prática, para além do aprendido, vai ao encontro da avaliação de Kvale (1992, p. 21) de que a teoria psicológica estaria "entrincheirada na modernidade", diferentemente da prática, esta sim, que tem que se confrontar "com a vida humana na pós-modernidade".

Uma segunda ressonância com a categoria 1 aparece na subcategoria intitulada a partir de um valor pessoal, onde se revela, atrelado à necessidade de ajudar, o sentimento de responsabilidade, tanto o "de qualquer profissional" como o "de cidadão", ou até mesmo "como missão". Os donos dessa responsabilidade são os mesmos que se mostraram anteriormente motivados para esse trabalho, pelas preocupações com a "desigualdade social" e com a "necessidade de ajudar".

A vivência de tal responsabilidade traz elementos para o conteúdo desta reflexão que levaram à formação da importante subcategoria denominada construção da identidade profissional, cujos elementos falam de um "lugar no social", diferente da clínica, exercido "de forma mais ampla", não consistentemente definido para as experiências desse grupo, de um lugar não valorizado, que "tem dono", em referência ao assistente social. A tendência revelada por várias das participantes é a de serem vistas, pelos demais profissionais, como psicólogas que têm uma atuação essencialmente clínica, que cuidam do intra, e não do social, que é um lugar, portanto, não só não valorizado como também não compreendido.
Tal percepção pode estar embasada em vieses na história da Psicologia como "projeto da modernidade" (Kvale, 1992, p. 21), que se originaria, por sua vez, da definição de social, considerado ainda como oposição ao individual, sendo negada a sua interconstituição (Grandesso, 2000, p.104), e, em consequência, a possibilidade de a ação psicológica ser vista como ação social.

A construção desse lugar, alimentada por um crescente comprometimento, comporta ainda elementos que vieram compor a subcategoria vivência de conflitos, que se refere às "demandas concretas da população" e ao impacto sobre o profissional, que se vê às voltas com o aspecto subjetivo de uma demanda por vezes tão concreta! Uma ajuda para esse impasse pode vir das lentes da complexidade, que apontam o trabalho com a intersubjetividade, o que significa favorecer a criação de um contexto que dê lugar à coconstrução de uma solução para as questões trazidas para o atendimento (Vasconcellos, 2002).

Um segundo conflito advindo do lugar do psicólogo na instituição vem do fato de ele se sentir, muitas vezes, situado entre os representantes das políticas públicas e das leis e a população atendida, e, para pelo menos duas das participantes, esse é traduzido como um lugar de "porta-voz da população". De fato, é muito bom pensar que essa população tenha quem a represente, quem se solidarize com ela, mas não como a voz defensora de uma única parte ou de uma realidade, quando se entende essa realidade como socialmente construída, que cria "verdades narrativas", e não "verdades históricas" (Grandesso, 2000; Vasconcellos, 2007), e tampouco como especialistas em suas vidas, pois, considerando-se que, dentro dessa leitura do mundo, a partir da complexidade, importam os significados construídos, tornamse eles, sim, os especialistas, como bem desenvolvem Anderson e Goolishian (1993) em O Cliente é o Especialista. 
As ideias e os valores das participantes, construídos a partir da vivência profissional com esses clientes e com o seu contexto de vida, foram apresentadas na categoria 3, intitulada a interface com o contexto da pobreza, cuja análise produziu cinco subcategorias. A primeira delas reúne elementos referentes à percepção da desigualdade social, e nela tecem críticas ao que seria a manutenção da pobreza, produzindo relatos de que eles, os pobres, viveriam a verdadeira realidade, desconhecida para nós e revelada para elas no atendimento nesse universo de trabalho. O risco dessa análise é o de ela estar comportando uma polarização eles/nós (Sarti, 2007) como se vivessem em um "universo cultural autônomo" (p. 45), levando-nos a desconsiderar que a pobreza é nossa! É essa uma importante contribuição de Walsh quando nos convida a pensar no sofrimento dessa população como "uma advertência da toxidade de nosso ambiente social" (p. 227).

A desigualdade é sentida também na relação psicólogo/cliente, visto pertencerem a diferentes classes sociais, correndo-se o risco de a realidade do profissional ser vista como referência. É desse risco que trata Macedo (2001) ao dissertar sobre a diversidade cultural como um desafio para o terapeuta, apontando como saída o constante autoescrutínio do profissional a respeito de suas "lentes culturais", em referência especialmente ao significado pessoal do poder profissional.

A força dessa diferença fica evidente na subcategoria ressonâncias da desigualdade nas atitudes da população atendida, em que são descritos como "mais resignados" na presença do profissional, muitas vezes, empenhados em se mostrarem "merecedores dos benefícios". Essa é uma provável consequência da política assistencialista, que não via a família como "sistemas complexos que se auto-organizam" (Sarti, 2007) e que pode ser ajudada a partir de seus próprios recursos, ou ainda como ressonância da chamada fase de dependência dentro do ciclo da pobreza, como desenvolve Paugam, considerando que "o mal-estar psicológico associado à pobreza pode ser mais cruel que a falta de bens materiais" (2003, p. 47), o que nos ajuda a compreender as demonstrações de inferioridade dessa população.

A terceira subcategoria desse item apresenta o conteúdo relativo à forma de o psicólogo viver essa relação em seu cotidiano de trabalho, e é denominada o impacto da relação com a pobreza. O impacto inicial está ligado à vivência da falta de recursos do profissional para lidar com as "questões concretas" do cliente, e pode gerar sentimentos de "impotência" e "estagnação" perante a realidade apresentada, o que constitui um desafio, visto aqui novamente como "um momento de aprendizado". Uma das participantes, recebendo apoio das demais, conta que tenta sair desse impacto fazendo não mais o "diagnóstico da falta", e sim, o "da potência", o que corrobora as críticas de Sarti (2007) a respeito das designações teóricas utilizadas para descrever essas famílias como "descritivas e estáticas" (2007, p. 20), centradas nos aspectos deficitários.

Designações com ênfase no processo seriam não apenas mais condizentes com a complexidade dos tempos pós-modernos como também mais eficientes no sentido de aumentar as possibilidades de solução, escapando-se de cronificar os prováveis sentimentos de impotência tanto dos profissionais como da população atendida. Pakman (1999) contribui enormemente para pensarmos sobre a falta de recursos do psicólogo para o trabalho na situação de pobreza, afirmando que a terapia psicológica apresentaria "limitações pragmáticas, teóricas e sociais" quando utilizadas nesse contexto. $\mathrm{O}$ autor ressalta a necessidade de "tratar a pobreza da terapia", considerando a dura realidade da rotina de atendimento nesse contexto de trabalho. 
Macedo (2001) nos fala do risco de, defensivamente, o profissional trabalhar com "distanciamento" do cliente e de sua impactante história de vida, protegendo-se em "automatismos" (p. 42) na atuação, da mesma forma que Pakman (1999) aborda as "pseudossoluções", que estariam apenas mantendo a estrutura total que mantém o problema" (199, p. 12).

A subcategoria os clientes no atendimento traz um conteúdo surpreendente, e até mesmo contraditório, à medida que fala muito positivamente desse encontro, contrariando as dificuldades advindas do impacto descrito anteriormente. Fala-se aqui de vínculos "mais fortes" e "mais afetivos", quando comparados com os atendimentos com a população do consultório particular, assim como de uma "bagagem de recursos" desenvolvida em função da vida na adversidade. Parece ter emergido aqui a imagem do "bom pobre" (Sarti, 2007, p. 45) em oposição à do "mau pobre", visto como representante "de todo mal social", uma visão idealizada da pobreza desenvolvida por solidariedade e pela necessidade de valorizar seus recursos.

Mas não só de elogios trata essa subcategoria, pois aponta também as reações agressivas, que podem ser compreendidas pela condição de desigualdade vivida nessa relação terapeuta/ cliente, e podemos recorrer a Paugam (2003), que, ao descrever as possíveis fases evolutivas do ciclo da pobreza, ajuda-nos a desenvolver maior compreensão para com os padrões de reação que podem emergir nesse contexto, para além da chamada disfuncionalidade. Nessa mesma linha de pensamento, contribui Hines com a reflexão de que as respostas dessas famílias, para não se darem por vencidas pela pobreza, podem ser adaptativas, por mais inadequadas que pareçam, revelando "um reflexo de grande criatividade e força" (1995, p. 442), mesmo sendo agressivas.
As críticas também aparecem na última subcategoria - os clientes na condução de sua própria vida, acrescidas aqui pelo que seria uma "vida sem planejar o futuro", marcada pelas necessidades imediatas e por apelos consumistas, "tirando da boca dos filhos". O grupo aqui se depara com a complexidade da vida pautada pelo consumo, e, ao mesmo tempo, para essas famílias, com a falta de acesso, que incrementa os múltiplos estressores que podem atingir suas vidas, sejam eles externos (desemprego, desabrigo, perdas), sejam internos, como os inerentes ao ciclo de vida das famílias (Cerveny, 1997). Esses estressores podem desestabilizar famílias em quaisquer condições socioeconômicas, mas de forma muito mais incisiva nas famílias pobres, que tendem a viver seu ciclo de vida sob impactos constantes, com crises que se sobrepõem e que demandam solução (Hines, 1995).

Contudo, os aspectos positivos aparecem em maior número nessa análise, destacandose a percepção de que eles seriam "menos resignados" quando "entre eles", surpreendendo pela solidariedade e pela forte adesão à comunidade. Tal resultado corrobora pesquisa portuguesa com famílias pobres (Sousa, Hespanha, Rodrigues, \& Grillo, 2007), que aponta relatos "menos saturados de problemas do que o dos profissionais" (2007, p. 225), assim como vai ao encontro da pesquisa de Sarti (2007), que investiga as categorias morais com as quais as famílias pobres constroem sua vida, na qual conclui que "a família pobre não se constitui como um núcleo, mas como uma rede", sendo regida pela "lógica da reciprocidade: dar, receber e retribuir" (2007, p. 93). Esse quadro pode nos levar a considerar que o pertencimento a uma rede de qualidade pode ajudar os indivíduos e suas famílias no cumprimento de suas tarefas pessoais e familiares, especialmente nesse contexto de múltiplos fatores estressores associados à pobreza. 
O tema da categoria 4 - a construção da relação com a população atendida" emergiu de reflexões a respeito de como se perceberiam vistos pela população atendida, reflexões essas que tomaram um rumo muito rico a respeito de como vai se construindo essa relação. O tema ajuda tomou o lugar central, causou novamente certo desconforto e provocou uma tentativa de redefinição da relação de ajuda. As participantes acabaram por perceber o desenvolvimento dessa relação como um processo cujos elementos puderam ser organizados em quatro subcategorias, que compuseram um quadro que pode resgatar a esperança.

As subcategorias contam dessa relação desde os momentos iniciais, que seriam marcados pelo poder profissional, e que deixariam os clientes "inseguros e temerosos", até mesmo por vê-los, os profissionais, como "representantes do juiz", instituindo em seguida uma relação marcada pela dependência, em que o profissional é idealizado como "especialista na vida deles". Essa fase de idealização iria sendo quebrada à medida que se conhecessem, psicólogos e população atendida, e surgiria uma relação marcada pela construção de ajuda, que seria, nesse momento, pautada pela "ajuda profissional", ou seja, pela "confiança" na competência profissional, e não pela suposta idealização e empoderamento deste. Estabelecida a relação de confiança, poderia manifestar-se o tão almejado momento para qualquer processo psicoterapêutico, de maior autonomia, dentro de uma relação que seria agora marcada pelo desenvolvimento.

Esse processo de construir a relação com a população atendida, percebido e revelado pelas participantes, pode estar, portanto, falando da real possibilidade de vivência de um processo psicoterapêutico nas condições de atendimento no contexto institucional.
Nossas colegas participantes ajudam-nos a perceber que, apesar de todas as dificuldades inerentes ao contexto da pobreza e às questões de identidade profissional nessa área de atuação, é possível viver um processo terapêutico, apesar do "momento injusto" (Waldegrave, 2000, p. 24) inicial marcado por uma assimetria de poder, cuja força poderia "manter as pessoas imobilizadas em situações de desvantagem ou injustiça". Essa preocupação levou Waldegrave a construir o conceito de just therapy, no qual afirma que, para uma "prática clínica efetiva" (p. 26), desenvolvida por "abordagens congruentes com o modo de vida da população atendida" (p. 28), os trabalhos deveriam ser desenvolvidos por pessoas da própria cultura. Nossos resultados mostram que é possível não só ultrapassar esse momento injusto como também transformálo em uma relação de crescimento.

Para avaliar esse momento injusto, recorremos a Macedo (2001), que nos ajuda a compreender a relação marcada pelo poder profissional como advindo da diferença sociocultural, em que o psicólogo representa a classe dominante e o cliente seria considerado um desviante, o que gera um poder instituído pela imobilidade social. Tal momento pode estar revelando a condição do cliente como a de um "subcidadão", conceito trazido por Souza para dar voz à constatação de que "a igualdade de direitos não se reflete na prática relacional" (2007, p. 14). É essa "desigualdade entranhada" que pode estar atuando nos primeiros encontros entre os psicólogos e os clientes desse contexto, causando distanciamentos marcados pelo medo e pela insegurança.

O que vemos aqui é que a ajuda pode vir de um profissional que "mantenha seu senso de competência, sem reforçar sentimentos de incompetência e impotência dos que buscam ajuda" (Macedo, 2001, p. 42), o que tornaria possível a travessia para as relações marcadas 
por confiança e desenvolvimento e faria o cliente voltar "a acreditar em sua capacidade de conduzir a própria vida, minimizando a sensação de desamparo e de baixa autoestima". Essa ajuda só se concretizaria (seja ela estar junto, ouvir, encaminhar, apoiar ou refletir) se acompanhada, segundo Grandesso (2000), da valorização do singular e do contextualmente situado, dando lugar às verdades narrativas, que colocam o foco nos significados construídos nas relações.

A importância dos significados construídos nas relações remete-nos à importância do tema as relações com a comunidade, apresentado pela categoria 5, que acaba por revelar a dificuldade de se considerar que as questões da comunidade fazem parte do campo de ação do profissional, sendo esse resultado configurado em quatro subcategorias, fruto do esforço do grupo para avaliar essas relações. Parece ter sido mais fácil pensar primeiramente sobre essas relações de forma sistematizada, uma subcategoria cujos elementos falam daquelas relações inerentes ao funcionamento da instituição, como a que se dá "via Juiz e Conselho Tutelar", "não por desejo", como esclarece uma das participantes, ou como a relação "com a rede de serviços". A forma não sistematizada refere-se às ressonâncias na comunidade dos trabalhos realizados na instituição, sendo a comunidade representada por aqueles "que vão até a instituição" ou "que chegam lá".

Junto a esses esforços para avaliar essa relação, surgem ainda afirmações que compõem a subcategoria pouco ou não considerada, fruto talvez de uma avaliação mais objetiva que fala de nenhuma relação de busca direta, ou de apenas uma pequena tentativa de aproximação. Apesar da constatação de dificuldades nessas relações, foi possível considerar e refletir sobre o fato de que elas são dotadas de ação terapêutica, o que forma uma última e importante subcategoria, que acaba por confirmar a possibilidade da existência de uma ação terapêutica nas relações com a comunidade, sendo o terapêutico considerado, nas palavras das profissionais, "não clínico", "diferenciado do processo clínico tradicional", e, por último, redefinido na expressão "clínica ampliada", colocada na forma de pergunta.

Refletindo sobre as condições para que a ação seja considerada terapêutica, usam a expressão "agente transformador", amparados em metáfora de semeadura. $\mathrm{O}$ autor dessa expressão faz-nos considerar os apontamentos de Fuks quando trata dos principais eixos da chamada Psicologia comunitária sobre a necessária passagem "da intervenção para a coconstrução", assim como sobre o "conflito entre a eficiência transformadora e o poder de decisão do outro" (1999, p. 02). Sua contribuição vai ao encontro dos cuidados com a legitimação do outro e da comunidade à qual pertence, cuidado esse presente também na importante pesquisa de Moré e Macedo, que se dedicou justamente a construir "um modelo de atenção à população dos serviços públicos" que fosse "voltado para a demanda". Foi um trabalho de vanguarda no que tange à construção desse novo lugar de atuação do psicólogo junto à comunidade, em um campo cuja complexidade foi se "transformando em elementos coconstrutores da proposta" (2006, p. 203).

A rotina da atuação das psicólogas participantes desta pesquisa é apresentada na categoria 6, intitulada a atuação como psicólogo na instituição, cuja análise produziu cinco subcategorias que tratam do tipo de ação desenvolvida, e duas que tratam de avaliar essa atuação ressaltando seus aspectos facilitadores e dificultadores.

Entre as cinco subcategorias que descrevem os tipos de atendimento, destaca-se o atendimento envolvendo famílias, não só por sua diversidade de ações como também 
pela relativa novidade da inclusão da família no campo do atendimento psicológico, antes restrito às orientações de pais de crianças e de adolescentes em atendimento. Aparecem aqui também os grupos multifamílias, uma prática em desenvolvimento, especialmente em contextos institucionais, que tem empolgado muitos dos profissionais e pesquisadores que com ela atuam.

Outras formas de trabalho com grupos são citadas e compõem a subcategoria atendimento grupal, que inclui os "grupos de reflexão", os "grupos de mães" e os "grupos de adolescentes". Uma expressão que se repete aqui é a que se refere à função do psicólogo nos grupos como facilitador, "não como coordenador", o que indica mudança no que tange à autonomia do sujeito, assim como à sua legitimidade, entendendo-se que um "facilitador" favorece o emergir de diálogos nos quais cabem diferentes lógicas e diferentes significados (Grandesso, 2000; Fuks, 1999), especialmente quando o psicólogo que está à frente do grupo não pertence à classe sociocultural dos participantes desse grupo e vive o desafio de trabalhar com a diversidade cultural (Waldegrave \& Macedo, 2001).

O atendimento individual aparece em sua forma tradicional apenas para uma das participantes que atua em instituição privada, que oferece justamente atendimento clínico para crianças e adolescentes. Esse tipo de atendimento não aparece nas demais instituições, que, por sua vez, parecem buscar alternativas para esse formato, respondendo aos objetivos de cada uma delas, o que despertou especial interesse no grupo e causou certa polêmica, que é a forma breve de atendimento. As participantes discutem o "não aprofundar" e o "ficar em questões práticas", e tentam avaliar seu poder psicoterapêutico. Surge também importante questão a respeito do atendimento do tipo breve para "famílias vulneráveis", que "apresentam tamanha complexidade".
Emerge a questão do tempo dedicado ao atendimento de um caso, cuja contrapartida seria o tempo livre, que pode gerar a "cronificação da presença das famílias nos programas" pela confluência de multiplicidade de fatores, inclusive pelas "pseudosoluções" (Pakman, 1999, p. 10) desenvolvidas pelos profissionais, perpetuando a "estrutura total que mantém o problema" ou, ainda, pela não integração interdisciplinar, cuja existência é preconizada pelo CREPOP (Brasília, 2007), que enfatiza, por intermédio da "interação de saberes e complementação de ações", "maior resolutividade dos serviços oferecidos".

A integração aparece em nosso grupo de participantes, principalmente mediante as "discussões com a rede de serviços", que, junto às "visitas domiciliares", compõem a subcategoria atendimentos externos. As participantes contam aqui sobre o aprendizado do trabalho com a rede, cuja importância foi sendo descoberta ao serem vencidas as resistências iniciais, e chegam a afirmar que "as discussões da família com a rede" fazem "parte da intervenção". Esses depoimentos ilustram aspectos de uma transição - da clínica para a instituição - que pede uma abertura não só para trabalhar na interface com profissionais de outras áreas como na interface entre as diferentes áreas da Psicologia.

Cabe aqui uma questão sobre os benefícios dessa abertura para a atuação do psicólogo de forma geral. Seria uma abertura da qual só se beneficiariam os profissionais da área social, ou podemos pensar que o trabalho junto às instituições tem provocado mudanças que estejam gerando novas competências que podem também pegar o caminho de volta e trazer novos ares para a clínica? Afinal, a metáfora do universo como rede vem justamente dar voz e lugar para o "sujeito complexo", aquele que "advém como tal na trama relacional de sua sociedade" (Najmanovich, 1998, p. 64), esteja ele no 
setting de um consultório particular ou na atividade grupal de alguma instituição.

É o mesmo sujeito complexo que se encontra nas visitas domiciliares, também citadas como parte dos atendimentos externos, que causaram certa inquietação ao grupo quando se discutiu o seu caráter "investigativo" para as "famílias de risco". Cabe aqui a lembrança de que se trata normalmente de famílias pertencentes aos grupos de aumentada vulnerabilidade, que têm diminuída sua capacidade de "controlar as forças que afetam seu bem-estar" por influência de múltiplos fatores que os mantêm no ciclo da pobreza (Paugam, 2003) e que geram respostas aparentemente disfuncionais que precisam ser vigiadas.

Voltando para a instituição, foram citados ainda os atendimentos fora da sala do psicólogo, subcategoria que trata das ações "que se dão a qualquer momento" nos diversos ambientes e situações de uma instituição. Nas instalações desta, muitas são as possibilidades de encontros, em diferentes condições, que podem se tornar palco de uma conversa de caráter reflexivo. Aqui nos ajuda Macedo (2004) ao defender a ideia de que o psicólogo clínico pode atuar em qualquer setting ou contexto, a partir de uma leitura da clínica como uma "atitude", uma "postura profissional".

Desenvolvemos, ao longo de nossas formações, diferentes capacidades que configuram nossa postura profissional e que podem estar a serviço do outro em diferentes situações. O lugar do psicólogo ficou tradicionalmente associado às quatro paredes de um consultório, dentro de um modelo clínico/médico, como se os fenômenos relacionais, ou a subjetividade, tivessem hora e lugar certo para se apresentar. Nas condições do atendimento particular, a instalação do consultório se justifica para possibilitar o encontro que se pretende terapêutico, efeito cuja garantia não vem das quatro paredes.

Entre os elementos considerados pelas participantes como dificultadores ao desenvolvimento de suas ações, ganhou destaque o excesso de controle administrativo e burocrático, que nos levou a pensar sobre os limites inerentes ao funcionamento de uma instituição, aos quais devem se adequar tanto a população atendida como os profissionais que ali atuam. Tratar desses limites nos encontros institucionais, na tentativa de compreender seus pressupostos, pode ajudar tanto no desenvolvimento de uma análise crítica do que ocorre como na construção de uma inevitável aceitação, que torna o funcionamento possível para todos. Como bússola para essa discussão, pode-se recorrer aos pressupostos éticos, inerentes à promoção da saúde (Westphal, 2007).

Junto às questões administrativas, estão as questões políticas, que expressam queixas tais como as mudanças repentinas de foco do trabalho, que parecem muito mais atreladas aos interesses da política partidária, que quase nunca se acha associada às legítimas preocupações com a saúde da população, e que deixa que suas ações funcionem como verdadeiros tratores demolidores de bons projetos em andamento.

Como aspecto dificultador, surge ainda um importante elemento, diretamente ligado ao trabalho do psicólogo no contexto social: a sua não valorização, tanto pela própria equipe de trabalho como pela população em geral. As reflexões tratam da expectativa percebida de que se faça a "clínica tradicional", o "atendimento individual", revelando assim a força do modelo médico vigente. As ações que diferem desse modelo tendem a ser não valorizadas, e até mesmo não aceitas, provavelmente por não serem compreendidas. 
É importante ressaltar que não há, na literatura consultada, nenhuma citação que advogue o fim do atendimento individual. O que muda, no olhar sistêmico novo paradigmático, é o significado do individual ou do self. É Grandesso quem afirma que uma psicologia da pós-modernidade não pode mais sustentar "uma visão essencialista do self" (2000, p. 55), que uma visão pluralista nos ajuda a compreender os selves como em constante processo, construídos nas relações com pessoas significativas presentes nas experiências vividas.

O aspecto social de que trata essa visão não tem, portanto, nem dono, nem lugar, nem hora marcada. Não pertence ao consultório e nem à instituição, mas ao indivíduo, que o carrega para onde for e que sofre as vicissitudes de cada encontro (a dois ou em grupo), pois, como bem nos lembram Macedo, Kublikowski e Santos, a construção da realidade se configura, do ponto de vista da complexidade, como "um processo individualmente cunhado e socialmente legitimado, em um processo recursivo entre indivíduo e cultura" (2004, p. 02).

Os aspectos facilitadores da atuação, última subcategoria desse grupo, trazem elementos relativos ao trabalho em equipe ou em rede, visto como parte inerente ao trabalho em instituições. As participantes, em seus depoimentos, falam de construir uma "aceitação" desse tipo de ação, em um exercício de abandono das vaidades profissionais que levam muitas vezes à ilusória posse de um caso, um exercício que envolve a aceitação do desafio de se desocupar o confortável lugar das certezas de um campo fechado de trabalho, onde não cabem outras visões ou diferentes lógicas. Tal enfoque começa a ser visto como algo imprescindível no trabalho em instituições - o encontro com diferentes profissionais que tratam da mesma população - portanto, como um benefício, um aspecto facilitador e enriquecedor do trabalho, que responde inclusive à urgência - a pobreza não pode esperar - que se instala frente à complexidade desse contexto.

É citado também como facilitador o "apoio da instituição", tanto no aspecto técnico e teórico (supervisões e cursos) como no aspecto material. Nesse momento, referemse à autonomia dada ao profissional na condução de seu trabalho, apesar dos empecilhos burocráticos e administrativos já apresentados. Talvez a saúde de uma instituição esteja condicionada à existência de uma estrutura bem definida, inclusive por seus limites, que dê a necessária autonomia a seus profissionais, tanto dentro de suas especificidades como no encontro com outras áreas. O norteamento para todas as ações estaria atrelado, em primeiro plano, aos objetivos da instituição, e, em um plano mais amplo, aos princípios éticos da promoção da saúde (Campos, 2007).

Por fim, foram citados os conhecimentos e as experiências anteriores, entrando aí apaixonados depoimentos de identificação com teorias e práticas, que incluíram os professores responsáveis. Os estágios aparecem como campos de potencial influência para a prática posterior, por serem justamente o lugar em que a teoria começa a encontrar o seu lugar junto a uma metodologia de trabalho. Os depoimentos, nesse momento, favorecem a percepção de como nossas escolhas têm a ver com o nosso "olhar para o mundo".

Dentro das atuais identificações favorecedoras do trabalho, citam o pensamento sistêmico, corroborando Santos quando afirma que "estando o pensamento sistêmico alinhado com a transição da ciência para a pós-modernidade, pode oferecer contribuições perante as novas demandas das humanidades" (1983, p. 63), ajudando a Psicologia a se renovar a partir de seu projeto 
de modernidade (Kvale, 1992). É citada também, com estranhamento, a influência dos pais, à medida que se dão conta de que esse "olhar para o mundo", que os motiva a estar nesse trabalho, inclui sua história de vida, indo, dessa vez, ao encontro do que afirma Cerveny (2000): os “padrões interacionais familiares refletem e contêm a maneira como o indivíduo experiência a realidade".

A categoria seguinte, número 7, denominada competências para o trabalho institucional, foi construída ainda com base no conteúdo da conversa sobre a atuação, quando deixam aparecer um conjunto de habilidades e atitudes desenvolvidas ao longo dos anos de trabalho nesse contexto, que, acrescidos do item conhecimento (cuja importância foi apontada em diferentes momentos desse grupo), compõem o conceito de competência, como desenvolvido por Fleury e Fleury (2001), aqui adotado por seu alinhamento com uma leitura de mundo construída a partir da complexidade. A análise desse conteúdo permitiu a construção de quatro subcategorias.

A primeira delas - para construir a relação terapêutica - fala de um conjunto de atitudes desenvolvidas provavelmente como resposta aos desafios do trabalho com a diversidade cultural, à medida que conferem especial cuidado à legitimação do outro na relação de atendimento. Os depoimentos nos permitem assistir a um especial esforço para assimilar diferenças que, por vezes, devem ser não somente grandes como também inaceitáveis, a ponto de levá-las ao exercício de considerar que, sim, "são gente como a gente!" É um movimento no sentido de se chegar a um cidadão legitimado que chamamos aqui de socialmente reconhecido, legitimado pelo pertencimento, pela visão da rede social que o inclui e que compõe um mesmo sistema social.
A essa questão, soma-se o cuidado com as questões do outro, que apontam as demandas que podem estar associadas às questões éticas como parte da competência profissional, tal como argumenta Rios (2004, p.20) ao tratar dessa competência considerando "o saber agir responsável". Nossas participantes destacam uma responsabilidade que vai além das questões técnicas, e mesmo políticas. É da dimensão ética que se fala aqui, aquela que, segundo Rios, faz uma "mediação" entre as dimensões técnica e política, quebrando uma possível dicotomia. Dentro dos cuidados, é levantado o risco de julgar de forma a não considerar a complexidade que envolve uma ação, que pode significar a distância de uma avaliação com ênfase no processo, que dá voz tão somente aos aspectos deficitários trazidos pelo encaminhamento.

Se as atitudes são abordadas por meio do cuidado, as competências associadas às habilidades, que compõem a subcategoria para a construção de estratégias e recursos, são abordadas através da criatividade. Parece que o contexto demanda o criar sempre, indicando, entre outros fatores, que as estratégias aprendidas anteriormente não dão conta dessa realidade, uma percepção que vem confirmar a avaliação de Andrade no sentido de que os processos de formação e capacitação ainda não têm garantido um "comprometimento social" com a "criação de novas formas de atuar e de intervir na realidade" (1999, p. 66).

A boa notícia, em nosso grupo, ainda no diálogo com Andrade, é que nossas participantes se referem a momentos em que o trabalho é exercido de forma a "acolher o processualmente emergente" à medida que se permitem ousadas e criativas, diferentemente dos que possam estar atuando "de forma alienante". O caminho parece ser o da criatividade e o da ousadia, saídas para o não empobrecimento da ação, um risco na difícil rotina desses profissionais, como 
nos alerta Pakman (1999), uma resposta às preocupações presentes na subcategoria para a relação com a instituição, relativa às possíveis ressonâncias da pobreza no trabalho do psicólogo.

O encontro com as adversidades faz aparecer a demanda por um profissional resiliente, não só perante a realidade da população como também perante a instituição. Surge aqui uma nova competência, a de "não esperar reconhecimento institucional ou social". Para a relação com a sociedade, destacam uma competência que aponta uma "responsabilidade" ou um "comprometimento", que dá ao psicólogo o lugar ou papel de "agente transformador", o que foi citado em diversos momentos nesse grupo.

Aparece uma competência que se refere às demandas desse trabalho que, em muitos momentos, extrapola o intrapsíquico, como afirmam Moré e Macedo (2006, p. 03) ao apontarem a necessidade de "outra postura" por parte do psicólogo que atende a população nos serviços públicos. Os autores introduzem o termo "trabalho clínico como ação social", no qual os fatores inerentes à pobreza necessitam ter a mesma importância que os fatores intrapsíquicos, uma postura de "profundo comprometimento com a justiça social".

Considerando a ajuda que metáforas podem dar à expressão de nossas percepções, principalmente quando ainda não se tem nomes e conceitos prontos para designar uma experiência, foi solicitado às participantes que apresentassem metáforas que falassem de suas percepções nesse contexto de trabalho, que vieram compor a categoria 8, cujos elementos produziram três subcategorias.

A primeira delas, imagens associadas a caminho e processo, refere-se a "pessoas escalando pedras", "um rio criando seu caminho", "como um jardineiro". As participantes falam de seu trabalho como uma caminhada que comporta riscos, no tatear para o próximo passo, que comporta cuidados no processo vivido enquanto se espera o resultado, que comporta adaptação e perseverança para continuar dando conta de cada nova demanda. É um retrato do que já haviam dito a respeito da construção de seu trabalho junto às instituições, onde afirmam ter aprendido com a convivência, tanto com o funcionamento da própria instituição quanto com a vida das famílias pobres. Elas ressaltam um envolvimento que depende tanto do que se traz como experiências e conhecimentos anteriores como do que se encontra pela frente. Assim como nos ensinam Anderson e Goolishian (1993, p. 13), há um "não saber" a ser considerado que gera o legítimo interesse pelo novo que se apresenta, assim como há "o conjunto de suposições e significados" que o profissional traz consigo, que, ao se encontrarem, abrem espaço para um novo significado como o "próximo passo".

As imagens associadas à composição artística, nas figuras de "mosaico" e "patchwork", também falam do uso do já existente em novas composições que se abrem para o novo, ou até para o inesperado, e do uso do que provavelmente seria descartado, como os caquinhos ou os pedacinhos de pano. As participantes destacam a capacidade de criar, já citada como competência necessária para o trabalho nesse contexto, mas de criar "juntando pedacinhos". Há que se descobrir recursos e competências, nem sempre percebidos como tal, quando se trata da vida em alto grau de vulnerabilidade.

$\mathrm{E}$, finalmente, as imagens associadas a sucesso e impotência - "como o deserto do Saara", "como uma praia paradisíaca" - permitem vislumbrar sentimentos os mais diversos, até mesmo opostos, associados à condução desse trabalho. A intensidade das imagens 
talvez reflita mesmo sentimentos próprios desse contexto, onde o sucesso ganha maior importância, e a possibilidade de fracasso, maior peso. Tudo aumenta perante a responsabilidade, já apontada aqui, de estar atuando no encontro com a dor e o sofrimento, cujos determinantes não se restringem ao intrapsíquico.

\section{Considerações Finais}

O percurso feito ao longo deste trabalho, norteado pelos seus objetivos, desde o contato com teorias e pesquisas que tratam da atuação do psicólogo junto às instituições que atendem a população socialmente vulnerável até o contato final, com os psicólogos que vivem essa prática, mostrouse instigante e produtivo. A riqueza dos encontros e diálogos, com teorias e práticas, trouxe fartura de reflexões e percepções, contrastando com o foco na pobreza, de onde, paradoxalmente, emergem questões que vêm alimentando os novos rumos da Psicologia em tempos pós-modernos.

Os binômios riqueza/pobreza, falta/ fartura, resignação/reação, impotência/ empoderamento são presença constante nessa caminhada, tanto quando são abordadas questões dos psicólogos e suas instituições como quando se abordam as vicissitudes da vida em contexto de pobreza. É o encontro desses dois universos que compõe o cenário desta pesquisa, assim como o conteúdo de suas principais cenas, que parece deflagrar um processo que tem o poder de desfazer dicotomias e de devolver o senso de competência a ambos, psicólogo e população atendida.

O novo lugar ocupado pelo psicólogo nesse contexto de trabalho, claramente percebido como em construção pelas participantes, parece acompanhar, ou até mesmo favorecer, uma renovação das formas de pensar tanto sobre a pobreza como sobre a Psicologia, quando analisado pelas lentes da complexidade. Foi o que se pôde apreender quando se refez essa caminhada retomando os resultados norteados pelos objetivos desta pesquisa. Para os propósitos deste relato, cabe aqui voltar ao objetivo geral desta pesquisa, o de desenvolver uma análise sobre a percepção dos psicólogos em torno de sua competência para trabalhar em instituições que atendem a população socialmente vulnerável. Essa análise se pauta principalmente na transição vivida por essas profissionais, que, ao terem se iniciado e persistido nesse trabalho, suportam os desconfortos inerentes a ele e não fogem às inquietações que pedem o desenvolvimento de novas competências.

Pode-se dizer que essa é uma transição favorecida pelos ventos do pensamento pósmoderno, um espírito de nossa época que permite o questionamento de velhas certezas, que podem perder seu status de verdade e dar espaço à imprevisibilidade. As certezas construídas pela Psicologia, como um projeto da modernidade, dentro de um modelo clínico/ médico, não se revelaram suficientes ou até mesmo úteis para essas profissionais quando em contato com seu novo campo de trabalho. Tal desencontro foi expresso de diferentes formas e em diferentes momentos.

A resposta dada pelas profissionais às dificuldades encontradas não foi a da estagnação ou a da tentativa de fazer caber o já aprendido, e sim, a da criação, já que se mostraram capazes de trabalhar com o imprevisto ou com o instável ao abrir mão do conforto do previsível, que, no caso da Psicologia, advém das certezas teóricas que acabam por enquadrar o comportamento humano; por isso, foram criando e questionando seu lugar, seu papel, sua função. Ainda não sabem denominar o que fazem, e tentam fazê-lo a partir do modelo clínico, que gera perguntas como: seria essa uma clínica ampliada? 
O termo ampliada surge, provavelmente, em função de um olhar que não pode mais levar em consideração apenas o intrapsíquico, que se depara, a todo momento, com o concreto dessas vidas em constante vulnerabilidade, um olhar que não pode mais negar os condicionantes socioeconômicos de uma vida saudável por perceber as ressonâncias da desigualdade social nas subjetividades e nas relações. O que se descortina a partir daí é a possibilidade de o interpsíquico passar a fazer parte do campo de trabalho do psicólogo, o que daria lugar à complexidade dos fenômenos e permitiria trabalhar com a contextualização dos problemas e das questões trazidas pela população atendida.

Dentro desse cenário de novos olhares, tornase mais fácil dar significado à preferência explicitada por essas profissionais ao trabalho com grupos, quando se referem aos clientes, e em equipes, quando se referem aos demais profissionais, ou ainda à rede de serviço. Os relatos são também de uma construção nesse campo, pois existem resistências, e até quem ainda não inclua equipes em sua rotina de trabalho. A formação do psicólogo não facilita sua participação em equipes que envolvam outros profissionais quando ainda se percebe e se é visto como dono do intrapsíquico e do individual, e até mesmo como guardião dessa individualidade.

Mas como nossas participantes afirmam estar se beneficiando dessa inserção para o desenvolvimento de seu trabalho, revelam novamente uma abertura cuja abrangência pode ser avaliada pela posição que percebem ocupar nos grupos realizados com os clientes de suas instituições, denominada facilitador, que não é mais a de um condutor ou orientador. Trata-se de uma posição que pode favorecer a emergência de um contexto que permita coconstruir uma solução, legitimando todos os saberes. A ajuda se constrói, portanto, na relação, na vivência da intersubjetividade, o que indica mais um passo na direção dos paradigmas emergentes da ciência contemporânea.

Esses são pressupostos alinhados com o pensamento sistêmico novo paradigmático, cuja influência foi de fato declarada pelo grupo e percebida como um abrir de janelas e de possibilidades nesse contexto de trabalho. Chama a atenção o fato de não aparecer, no conteúdo de seus relatos, referências ao discurso tradicional da Psicologia, que envolve constructos da psicopatologia e do modelo médico, de diagnósticos, tratamentos e prognósticos. Nenhuma dessas ações está incluída no grupo de competências percebidas como necessárias para o trabalho nesse contexto, cujas demandas parecem mesmo escapar à clínica tradicional, abrindo espaço para as questões relacionais típicas da contemporaneidade, que não mais podemos compreender pelos antigos paradigmas.

Como vivem, assim, a relação com as teorias aprendidas que vêm norteando sua prática? Não se percebe nesse grupo a predominância de narrativas teóricas pré-assumidas, e sim, uma tentativa de valorizar as verdades narrativas, legitimando os significados construídos por todas para sua própria história de vida. As participantes ainda citam teorias de forma reificada, como se fosse possível compreender e classificar todas as vivências relacionais a partir de seus constructos teóricos. A competência aqui exigida é a de que se possa trazer o conjunto de suposições e significados, construídos ao longo dos anos de formação e pós-formação, para o diálogo com o outro, a ser compartilhado e significado conjuntamente.

É esse o ponto que, marcando o lugar do terapeuta no encontro com o cliente, trabalha uma nova ideia de comprometimento social, aquele que inclui o outro em igualdade de condições, e não de papéis, crenças, valores. Há também um compromisso de tolerância e de assimilação das diferenças, 
um comprometimento que permite rever o processo terapêutico e dar a ele o status de uma conversação terapêutica. Foi nas tentativas de definir e redefinir a ajuda psicológica e o aspecto terapêutico que esse grupo avançou na construção de seu comprometimento social, que acabou se transformando a partir do comprometimento inicial, que as havia motivado pela necessidade de ajuda frente às perversas consequências da desigualdade social.

A transição não traz certezas, mas vem movida por inquietações e dúvidas que aqui se revelam. Mas traz descobertas e possibilidades, o prêmio de quem se permite dar voz às inquietações. Há um tom de liberdade e de criação nos preciosos depoimentos que aqui pudemos conhecer. Essas psicólogas, que gentilmente compartilharam suas vivências e reflexões, fazem a história da Psicologia no advento do pensamento pós-moderno.

As metáforas construídas por elas ao final do grupo focal para apresentar, em uma imagem, suas percepções a respeito de seu trabalho, revelaram-se muito apropriadas para responder ao problema que motiva esta pesquisa, aqui reapresentado: como os psicólogos percebem sua atuação junto às instituições que atendem a população que vive em situação de vulnerabilidade social na região de São José dos Campos, perante as demandas de maior comprometimento social?

As metáforas, assim como o conjunto de seus depoimentos, falam de um lugar em construção, em que trilham caminhos e vivem processos, a respeito dos quais ainda constroem uma consciência, um trilhar que exige que se tateie cuidadosamente perante a delicadeza do terreno. Esse tatear se torna possível pelo que já se trilhou, e útil pelo que se descortina, o não saber implícito e considerado não como uma incompetência, mas como parte do processo, e, principalmente, como mobilizador do encontro que abre para o novo.

Esse caminhar constrói identidades, provoca redefinições e dá a si mesmo, como profissional, e ao outro, como cliente, um novo lugar, marcado por um comprometimento de legitimação de diferenças que carrega em si um poder terapêutico. Das demandas desse comprometimento que chamamos social, que estão sendo conhecidas passo a passo, emerge a ética das relações, como bússola e como fonte de reflexões.

Os pedacinhos do mosaico e do patchwork em composição artística acrescentam a essa resposta a surpresa de cada nova configuração, que se torna possível pelos diferentes lugares ocupados em cada construção, cada uma com seu sentido e seus efeitos próprios. Não há um lugar certo para todas as situações. A atuação nesse contexto parece ter possibilitado, ou simplesmente ter reforçado esse olhar, que admite, além do não saber, o reconhecimento das diferentes configurações como legítimas, em um exercício de flexibilidade e tolerância.

Por último, como demanda desse comprometimento, fica a grande responsabilidade que daí emerge, em um caminho sem volta, como o do rio, que segue sempre em frente, criando caminhos, desviando-se de obstáculos, formando um lago... Assim se dá com um verdadeiro comprometimento, não há volta. 


\section{Referências}

\section{Maria José Lima}

Doutoranda em Psicologia Clínica, núcleo de Família e Comunidade da Pontifícia Universidade Católica de São Paulo, SP - Brasil.

E-mail: majo.sjc@gmail.com

\section{Ceneide Maria de Oliveira Cerveny}

Doutora em Psicologia Clínica pela Pontifícia Universidade Católica de São Paulo. Professor assistente da Pontifícia Universidade Católica de São Paulo, São Paulo - SP - Brasil.

E-mail: ceneidecerveny@gmail.com

\section{Endereço para envio de correspondência:}

Rua Máximo Brogliato, 241. Cond. Altos da Serra I. Bairro Urbanova II.

São José dos Campos, São Paulo - SP - Brasil. CEP: 12244-493

Recebido 26/4/2011, 1a Reformulação 7/9/2011, Aprovado 10/1/2012.

Anderson, H., \& Goolishian, H. (1993). O cliente é o especialista. Uma abordagem para terapia a partir de uma posição de não saber. Revista Nova Perspectiva Sistêmica, 3, 8-23.

Andrade, Â. N. de. (1999). Psicólogo(a) clínico(a) e a atuação em comunidade: incertezas e desafios para sua formação. Psykhe, 8(1), 65-71.

Brasil. Lei Orgânica de Assistência Social - LOAS. Lei nº. 8.742, de 7 de dezembro de 1993. Brasília, DF: autor

Campos, G. W. de S., et al.(2007). Tratado de Saúde Coletiva. (2a. ed.). São Paulo: Ed. Hucitec

Centro de Referência Técnica em Psicologia e Políticas Públicas CREPOP. (2007). Referência técnica para atuação do psicólogo no CRAS/SUAS. Brasília, DF: Conselho Federal de Psicologia.

Cerveny, C. M. de O. (2000). A família como modelo. Desconstruindo a patologia. Campinas, SP: Editora Livro Pleno.

Cerveny, C. M. de O., \& Berthoud, C. M. E. (1997). Família e ciclo vital. Nossa realidade em pesquisa. São Paulo: Casa do Psicólogo.

Chizzotti, A. (2001). Pesquisa em ciências humanas e sociais. (5a. ed.) São Paulo: Cortez

Fleury, A., \& Fleury, M. T. L. Construindo o conceito de competência. Recuperado em 20 de maio de 2009 de www. anpad.org.br/rac/vol5/dwn/racv5-edesp-mtf.pdf.

Fuks, S. (1999, maio). Memórias em psicologia comunitária. Psykhe, 8(Esp.), 1-194.

Grandesso, M. (2000). O individual e o social: em busca da complexidade. In M. A. Grandesso. Sobre a reconstrução do significado: uma análise epistemológica e hermenêutica da prática clínica (pp. 104-116). São Paulo: Casa do Psicólogo.

Hines, P. M. (1995). O ciclo de vida familiar nas famílias negras pobres. In B. Carter \& M. McGoldrick. As mudanças no ciclo de vida familiar (2a. ed.). Porto Alegre: Artes Médicas.

Kvale, S. (1992). Postmodern psychology: A contradiction in terms? In Psychology and post modernism. Califórnia: Sage Publ.

Macedo, R. M. S. (2001). Diversidade cultural: desafio para o terapeuta familiar. In M. A. Grandesso (Org.), Terapia e justiça social: respostas éticas a questões de dor em terapia (pp. 41-48). São Paulo: APTF.

Macedo, R. M. S., Kublikowsky, I., \& Santos, M. G. (2004). A interpretação em pesquisa qualitativa: a construção do significado. In Anais da primeira Conferência Internacional do Brasil de Pesquisa Qualitativa (p. 83). Taubaté, SP.

Macedo, R. M. S., Kublikowsky, I., \& Santos, M. G. (1984). Psicologia e instituição: novas formas de atendimento. São Paulo: Cortez.

Moré, C. L. O. O., \& Macedo, R. M. S. (2006). A psicologia na comunidade: uma proposta de intervenção. São Paulo: Casa do Psicólogo.
Najmanovich, D. (1998). El lenguaje de los vínculos. De la independência absoluta a la autonomia relativa. In E. Dabas \& D. Najmanovich. Redes in el lenguaje de los vínculos. Buenos Aires: Paidos.

Oliveira, S. M. (2003). Família e pobreza. In S. M. Oliveira. A reconstituição da família: um estudo das famílias que voltaram a viver juntas após um período de institucionalização dos filhos. (p. 35) Dissertação mestrado, Pontifícia Universidade Católica de São Paulo, SP

Oliveira, A. L. de. (2008). Análise de conteúdo. Universidade de Taubaté, SP. (Material não impresso).

Pakman, M. (1999). Terapia familiar em contexto de pobreza, violência, dissonância étnica. Nova Perspectiva Sistêmica, 8(13), 6-25.

Paugam, S. (2003). Desqualificação social. Ensaio sobre a nova pobreza. São Paulo: Cortez Ed.

Rios, T. A. (2004). Ética e competência (14a ed.). São Paulo: Cortez.

Santos, B. de S. (1999). Um discurso sobre as ciências na transição para uma ciência pós-moderna. In B. Santos. Introdução a uma ciência pós-moderna. Rio de Janeiro: Graal Ed.

Sarti, C. A. (2007). A família como espelho. Um estudo sobre a moral dos pobres (4a ed.). São Paulo: Cortez.

Sousa, L., Hespanha, P., Rodrigues, S., \& Grillo, P. (2007). Famílias pobres: desafios à intervenção social. Lisboa: CLIMEPSI Editores.

Souza, J. de. (2007). Democracia e subjetividade: a produção social dos sujeitos democráticos. Jornal do Federal, 20(87), 14-15.

Vasconcellos, M. J. E. de (2002). Pensamento Sistêmico: o novo paradigma da ciência. Campinas, SP: Pappirus,

Vasconcellos, M. J. E. de ; Coelho, S. V.; \& AUN, J. (2007). Atendimento sistêmico de Famílias e Redes sociais. (Vol. II). Belo Horizonte, MG: Ophicina de Arte e Prosa

Waldegrave, C. (2001). "Just therapy" com famílias e comunidades. In M. A. Grandesso. Terapia e justiça social: respostas éticas a questões de dor em terapia (pp. 19-36). São Paulo: APTF.

Walsh, F. (2005). Fortalecendo a resiliência familiar. São Paulo: Roca.

Westphal, M. F. (2007). Promoção da saúde e prevenção de doenças. In G. W. de S. et al. (Orgs.), Tratado de Saúde Coletiva (2a. ed., pp.635-666). São Paulo: Ed. Hucitec, Rio de Janeiro: Ed. Fiocruz 